\title{
1 Sudden changes in nitrogen dioxide emissions over 2 Greece due to lockdown after the outbreak of COVID-
}

319

4 Maria-Elissavet Koukouli ${ }^{1 *}$, Ioanna Skoulidou ${ }^{1}$, Andreas Karavias ${ }^{2}$, Isaak Parcharidis ${ }^{2}$, Dimitris

5 Balis ${ }^{1}$, Astrid Mandrers ${ }^{3}$, Arjo Segers ${ }^{3}$, Jos van Geffen ${ }^{4}$ and Henk Eskes ${ }^{4}$

61 Laboratory of Atmospheric Physics, Aristotle University of Thessaloniki, Greece.

72 Department of Geography, Harokopio University, Athens, Greece.

83 TNO, Climate, Air and Sustainability, Utrecht, The Netherlands.

94 Royal Netherlands Meteorological Institute (KNMI), De Bilt, The Netherlands.

10 * Correspondence: mariliza@auth.gr 
$14 \quad$ Figure S1.

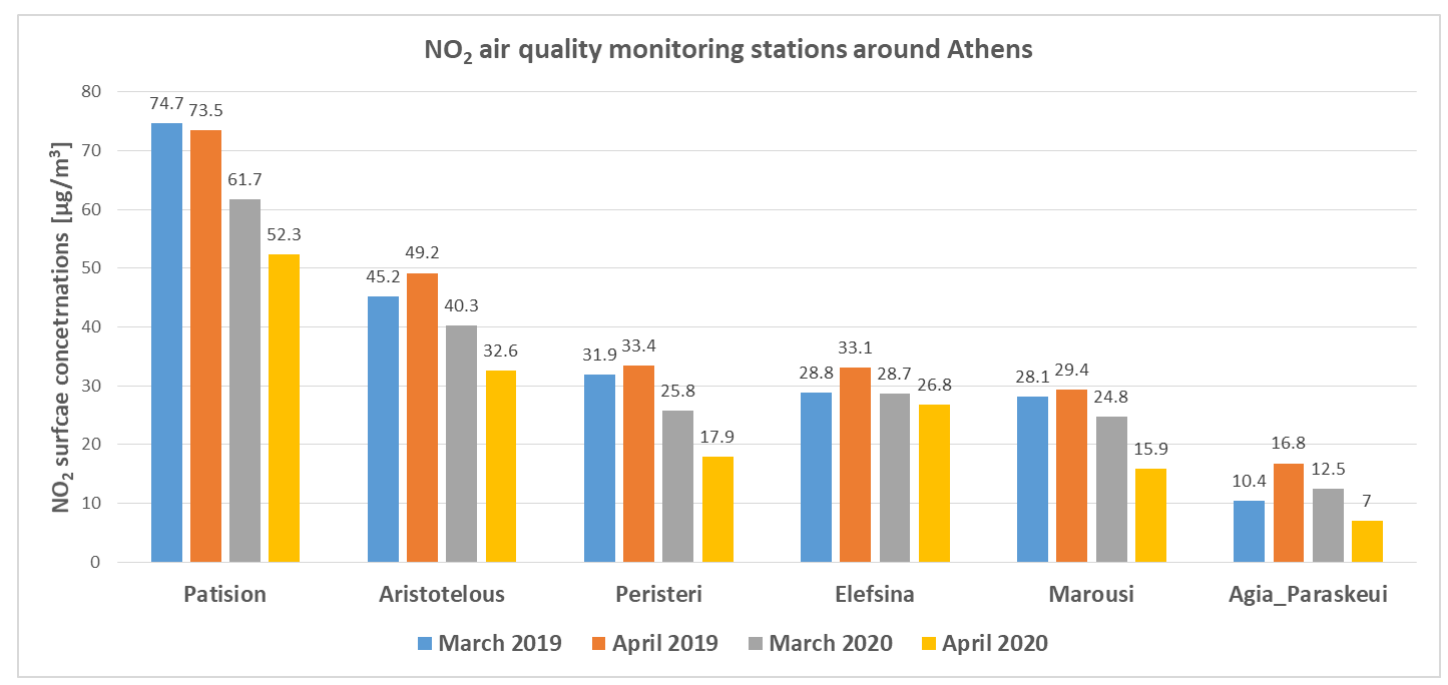

15 Figure $\mathrm{S} 1$. In situ observations of $\mathrm{NO}_{2}$ surface concentrations $\left[\mu \mathrm{gr} / \mathrm{m}^{3}\right]$ by air quality monitoring stations around Athens 16 reporting to the EEA Air Quality Database. 

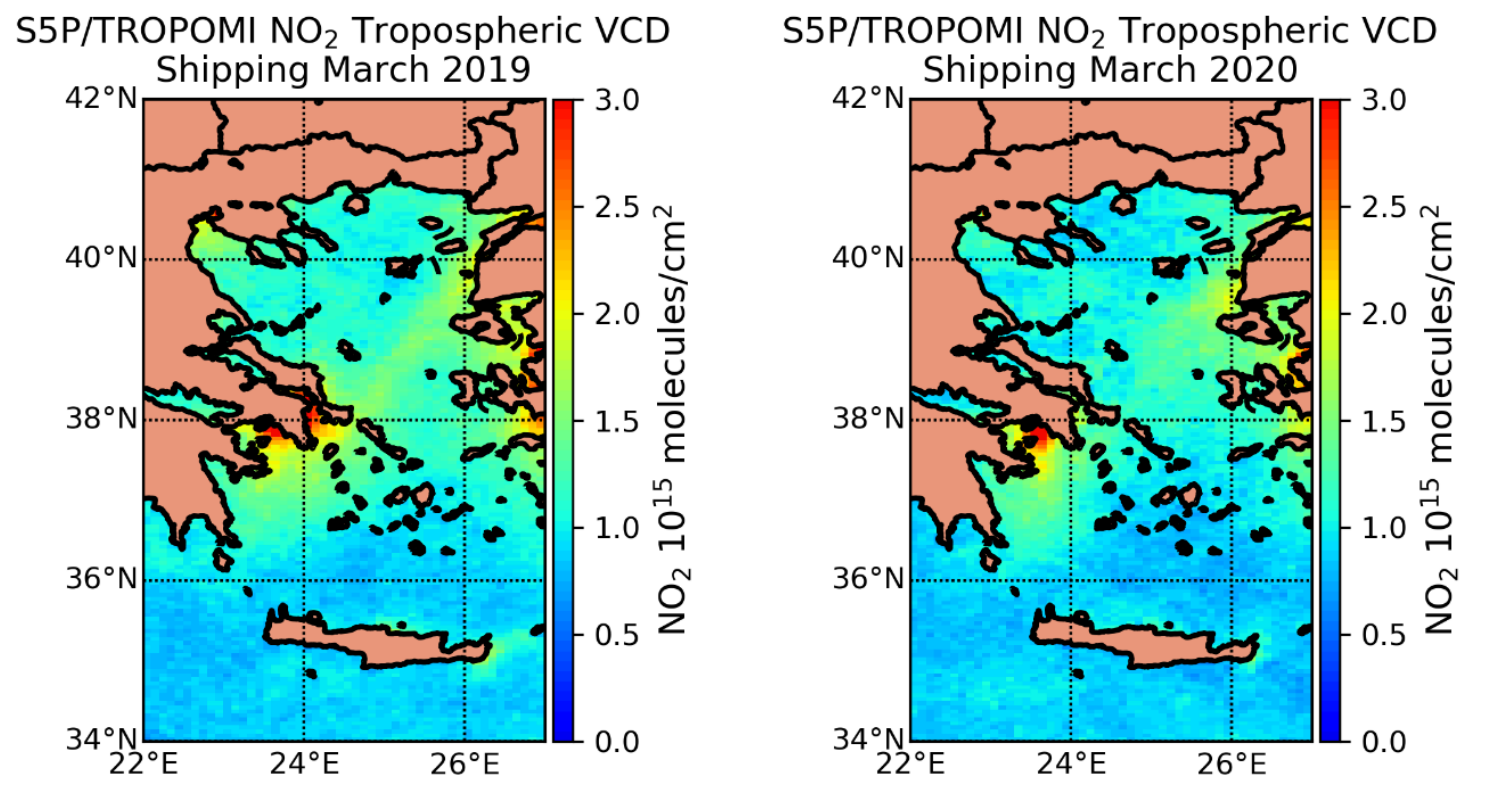

Figure S 2. Monthly mean S5P/TROPOMI tropospheric $\mathrm{NO}_{2}\left[10^{15}\right.$ molecules $\left./ \mathrm{cm}^{2}\right]$ over the Aegean Sea in 2019 [left] and 2020 [right] for the month of March.

(1)

(C) 2020 by the authors. Submitted for possible open access publication under the terms and conditions of the Creative Commons Attribution (CC BY) license (http://creativecommons.org/licenses/by/4.0/). 